\title{
Sharing of Learning Material on Mobile Devices through Bluetooth Technology
}

\author{
doi:10.3991/ijet.v5i1.1170 \\ M. A Otair ${ }^{1}$, M. Al-Jedaiah ${ }^{2}$, A. Al-Zoubi ${ }^{3}$ and A. Al-Refaee ${ }^{1}$ \\ ${ }^{1}$ The Arab Academy for Banking and Financial Sciences, Amman, Jordan \\ ${ }^{2}$ Al-Ahlyyia Amman University \\ ${ }^{3}$ Princess Sumaya University for Technology
}

\begin{abstract}
Education institutions are faced with the challenges of introducing new technology-enhanced learning services and utilize emerging technologies to enhance the efficiency of the learning process. Mobile learning provides the ability for users to learn anytime and anywhere using handheld devices with direct access to learning material. In developing countries, internet subscription is still expensive, which makes mobile learning as the most suitable bridge to access learning materials without much additional cost to be connected with the learning materials. In this paper, a new mobile learning system which aids tutors to transfer learning material files to learners' mobile devices through Bluetooth technology is developed.
\end{abstract}

Index Terms - Bluetooth, M-learning, and PDA.

\section{I. INTRODUCTION}

Electronic Learning (E-Learning) uses electronic tools to make the learning process easier, throughout tasks as information sharing and collaborating. Mobile learning (Mlearning) has similar functions as E-learning; however, it can be achieve these tasks by using mobile devices [7]. Ultimately, M-learning may be consiered as any ELearning application delivered via mobile technology [7]. M-learning is a link between mobile computing and ELearning that intersects to support learning practices an anytime and anywhere. The progress in mobile technologies have improved M-learning tools to obtain the need for more costly training and learning options. M-learning can present a lot of methods that reduce the limitations of traditional education more than E-learning [5]. The usage of mobile devices for mobile learning is becoming gradually more accepted. There is a new brand of learners in the universities now-a-days who are easily connected to technology and modern mobile devices [11].

The mobile learning depends on the use of mobile devices anywhere and anytime such as: pocket size computers (PDAs), notebooks, cell phones, smart-phones or even Tablet PCs [10]. These devices must be able to offer teaching materials, and to realize an asynchronous/synchronous communication between learners and tutors. The wide existence of mobile devices and wireless technologies might realize using different systems for mobile education [9].

The traditional learning is used in classrooms where tutors can present the learning material to the learners. The tutor and the learners who must participate physically in the learning process are basically very important for educational technology. Regardless to the aspects of the direct contact between the tutor and the learners; the traditional education has a lot of negative aspects. For instance, if a learner is not able to attend the lesson in the class, he/she will miss the training part of the class. These negative aspects lead to look for more and new effective learning methods. However, E-learning can offer new methods for education by using computer and internet technology. As shown in [5], M-learning comes out of intersecting of mobile computing and E-learning. M-learning can be able to teach anywhere and anytime without any human or physical connection to networks. Wireless systems and mobile include: mobility and computing [5]. According to [1], they have been improved both by making mobile devices more suitable and affordable and M-Learning as a real education world.

For mobile developers, mobile learning is becoming popular. Mobile learning means the provision of learning materials and courses on wireless devices: portable computers, PDA's (personal digital wireless devices), and mobile telephones [12]. This paper concentrates on PDA, as a handheld computer. As mentioned in [12], when a tutor, a learner, or an administrator use PDA, they can produce amazing things such as: calculating, accessing resources, taking notes, sketching ideas, collecting data, managing activities and accessing wireless Internet with the suitable hardware. However, handheld computers can be less beneficial and useful to learners and tutors.

A most popular, but more modern, wireless networking technology is Bluetooth. These networks are commonly used as a method for connecting multiple mobile devices to each other for data sharing purposes. Using a Bluetooth it is easy and quick for a learner to share data between multiple electronic or mobile devices; mobile to PDA, PDA to mobile, laptop to PDA for wireless hot synchronization operations, whatever the necessity of exchanged data. This implementation offers the mobile usability and also facilitates the use of mobile devices for M-learning applications [7]. So, this paper presents a new mobile learning system which aids tutors to transfer learning material files to learners' PDAs and vice versa through Bluetooth technology.

This paper consists of 6 sections as follows: In section 2 the types of mobile devices were presented, while in section 3 the types of wireless communication technology were explained. In sections 4 and 5 the developed system with its implantation were introduced. Finally, in section 6 we conclude the paper. 


\section{Mobile Devices}

M-learning defines what kinds of devices are parts of? Presently, there are three main devices used in M-learning environment, the mobile phone, the MP3 player, and the personal digital assistant (PDA) $[16,3]$. Each of these devices offers distinctive M-learning systems to the user that will be examined independently, but increasingly there are also combination devices that include the functionality of multiple of these devices [7].

M-learning can help learners access lesson resources, download media and collaborate with other learners if there Internet access in their mobile devices. This connectivity gives the learners the opportunity to get important messages related to the class, while waiting in line for lunch, sipping their morning coffee or walking between classes in the campus [7]. M-learning gives the learners true information and it also gives them an opportunity to participate to take part in the learning process at anytime $[13,19]$.

If an adequate hardware and Internet resources are available, then the next task is to choose the kind of Mlearning technology that would be activated [7]. Mlearning design phase should include the content and design of information delivered to the learners, places that users work in, and the kinds of devices that the users can access [15].

The device is of M-learning an important element. Consequently, device produceres are doing their best to develop a wider variety of products [20]; therfore, the coming services will need alot of characteristics which makes the downloading material easier in several kinds of format such as: text, voice and video. The PDA might to be considered as the first mobile device comes to mind. PDA computers offer many features of full-size laptop computer which fits a pocket. Mobility is a essential elemnent of M-learning hardware [10]; however, few devices provide mobility and PDA features at the same time.

The most popular kinds of mobile devices can be used in the learning phases are [5]:

- Notebook computers: they can do what personal computer do; they have small sizes and they can support wireless networks. However, their prices are expensive.

- Tablet PC: These are very new mobile devices, and they can do what personal computer do. Some of these computers have no keyboard but they have software recognize handwritten text. Finally, this kind of mobile devices can be considered expensive.

- Cellular phones: They are low class devices which can be used for sending and receiving of text messages (SMS) and communication via voice. They have low memory and low data transfer rate. The higher class of cellular phones can be used to access Internet via GPRS or WAP. They also can be used for sending and receiving MMS. Finally, their prices are decreasing continuously.

- Smart phones: They are hybrid devices that have the abilities of cellular phones and PDA. Their sizes are smaller than PDA. They don't have full sized keyboard, but it can recognize handwritten text. Symbian Windows Mobile and other operating system can be used. They have browsers which might be used in mobile education. Now days, communication tech- nologies in mobile devices have been improved, so, their abilities and their data transmission range are variant [8].

- Personal Digital Assistant (PDA): Their sizes are small and they have a strong processor power. Their new products models have more than 65000 colors which can recognize handwritten text and play several multimedia files. The main operating systems that used in these devices are Microsoft Pocket PC and Palm. Moreover, PDAs form a good combination of digital storage along with computing power, internet access, wireless network access through Bluetooth or $\mathrm{Wi}-\mathrm{Fi}$, and stylus input interface or pen, along with other word processing tools. It lets learners' access web content and email and can play multimedia files. It can support group learning and interactivity.

\section{WiRELESS COMMUNICATION TECHNOLOGIES}

Because PDAs enable users to participate work by "beaming" files via Bluetooth or infrared from one user's PDA to another, group effort, encouraging collaboration, involving peer reviewing, and sharing of information [17]. Bluetooth is not like infrared. It does not require off-line sight between devices to create and keep a data connection [18]. Thus, the success of mobile devices and wireless communication technology has enabled different activities and applications to be ported into mobile mode from desktop platform [21].

The most common kinds of wireless communication technology used in the learning process are [2]:

- 3GP: it is used to delivery method of audiovisual content which is associated with Mobile Learning.

- Wi-Fi: it gives the learners an access to tutors and resources via internet.

- General Packet Radio Service (GPRS): it is an always-on internet and mobile data services. It gives high speed connection and data transfer rate.

- $4 \mathrm{G}$ : it is the $4^{\text {th }}$ generation mobile telephone technology. It comes as successor of $3 \mathrm{G}$. Every new generation of mobile technology can play an important role in a change on M-learning business model.

- Bluetooth: is a short-range wireless technology that is used to send data between other Bluetooth devices. For instance, the PDA in the learner hand can receive message from the mobile in his/her bag.

Bluetooth wireless technology is used to replace the cables by portable or fixed electronic devices. Bluetooth is now the largest radio-based technology after GSM [4]. Some of the most significant characteristics of Bluetooth (which will be used in the developed system) are given below:

TABLE I.

CHARACTERISTICS OF BLUETOOTH WIRELESS TECHNOLOGY

\begin{tabular}{|c|c|c|}
\hline Data Rate (Mb/s) & Range (meters) & Frequency Band \\
\hline $1-2$ & 100 & $2.4 \mathrm{GHz}$ \\
\hline
\end{tabular}

As shown in table 1, Bluetooth has three classes that can offer varying ranges of data connectivity [14]: Class 1 $(100 \mathrm{~m})$, Class $2(10 \mathrm{~m})$ and Class $3(1 \mathrm{~m})$. 


\section{THE DEVELOPED SYSTEM}

Innovation in information technology lies at the heart of any future planning in general and E-learning and $\mathrm{M}$ Learning in specific. Recently, this concept has actually received a significant attention and is currently considered as the courier of the next future of learning modes due to the growing in mobile devices and wireless networks. However, mobile applications seem natural to digital natives such as incoming learners, but not for the vast majority of tutors.

This paper presents a new mobile learning system which aids tutors to transfer learning material in the form of text, images, audio, video and XML files to learners' mobile devices through Bluetooth technology. The aim of the developed system is to: access to/sharing of learning materials on mobile devices through Bluetooth technology. The system software is written in C\#.net and mostly depends on XML files as they occupy a small memory size, giving the system an advantage in terms of performance and transmissions speed.

The idea of the developed system comes from the situation of the learners in Jordan as one of the developing countries, where the learners come to their universities from too far different towns once or twice a week (we talk here about The Arab Academy as a special case). Moreover, internet subscription is still expensive and not available for everyone, which makes mobile learning as the most suitable bridge to access learning materials without much additional cost to be connected with the learning materials.

The system software can be downloaded/uploaded easily from/to any mobile device and provides many capabilities and functionalities to users. The tutor can enter information about learners such as username and password; create text and XML files as notes or questions. In addition, the system acts as an efficient platform for interaction between learners and tutors with the added advantage of facilitating a means for making conversation.

Materials are organized in an easy form that can be loaded onto a learner's mobile device without changing the format. Moreover, the material can be available in several formats to be compatible with various devices. The Mobile document can provide tutors and developers in improving M-learning resources and its activities in the most suitable forms.

According to the information and communication technologies the proposed classification of the developed system is based on the following main indicators:

- the type of supported mobile device - PDAs;

- The type of wireless communication which is used to access learning materials and administrative information - Bluetooth.

As the permanent Internet connection is very important between the mobile learning system and the users to have the teaching materials on mobile device, the mobile learning systems can be presented following [9]:

- Systems for on-line mobile learning, which need a permanent communication between the system and the mobile device of a learner.
- Systems for off-line mobile learning. The material is already uploaded in the learners' device without any need for wireless communication.

- Systems, which ensure both on-line and off-line mobile learning. The learner can access part of the learning material on-line and the other part off-line while the material should be uploaded to the memory of the mobile devices before.

So, the developed system is categorized into the second category, which means it is off-line mobile learning system. Deploying M-learning materials can support equal access to learning by providing materials in a range of formats. Consequently, a learner who is unable to access a version of the learning activity using a web browser or via downloadable or print based resources should still be able to access a mobile learning resource using a mobile phone, media player or PDA.

System requirements were defined by tutors and other important constraints such as the lack of any infrastructure to Internet connection for each university have influenced technological choices in the implementation of the working environment.

The developed system is packaged into PDA's and mobiles devises and it's easy to download, this system is written in C\#.net programming language, the questions and assignment can created by special text editor appropriate to that work and by XML files used to database because the XML file has a small size or volume in memory, in windows CE operating system.

\section{THE IMPLEMENTATION OF THE SYSTEM}

This section presents the developed system with its interfaces for all sides in details. The developed system is divided into three sides: The administrator, tutor, ad learner side respectively.

\section{A. Administrator Side}

Using the following figure the administrator of the system can add a new tutor or learner, so we have two cases:

The first case: the new user is tutor.
A. Enter the user name and;
B. Enter his password
C. Select a Tutor Radio Button
D. Click on the $A D D$ button

The second case: the new user is learner.
A. Enter the user name and;
B. Enter his password
C. Enter the password of his tutor, and then the tu- tor who has this password will be the receiver of all the files from this learner.
D. Select a Learner Radio Button
E. Click on the $A D D$ button

\section{B. The Tutor side:}

At this side ther are many useful interfaces for the tutor. However, the mostly used interfaces are shown in figures 2 to 6. 


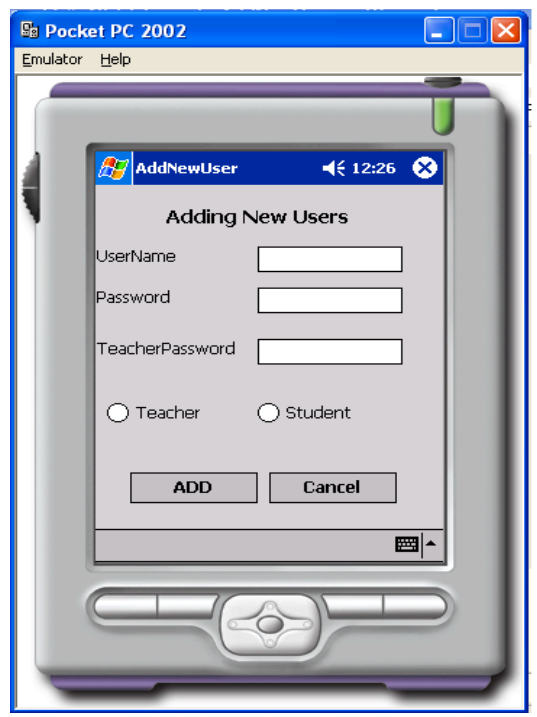

Figure 1 Administrator Interface

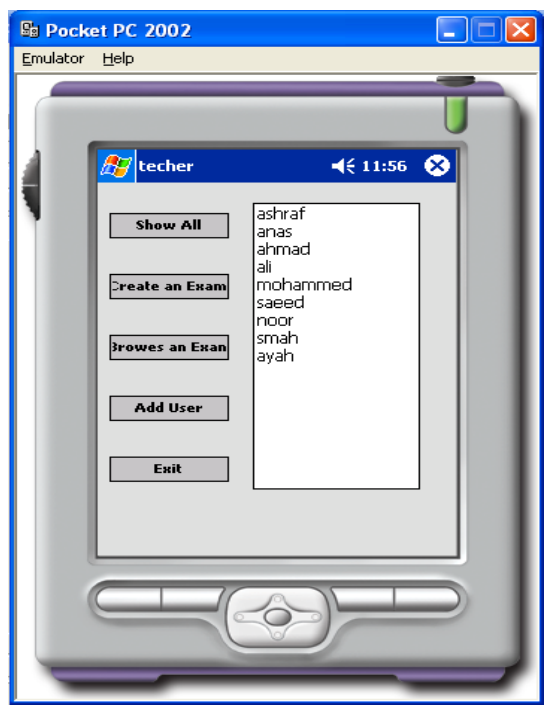

Figure 4 Online Stdudent

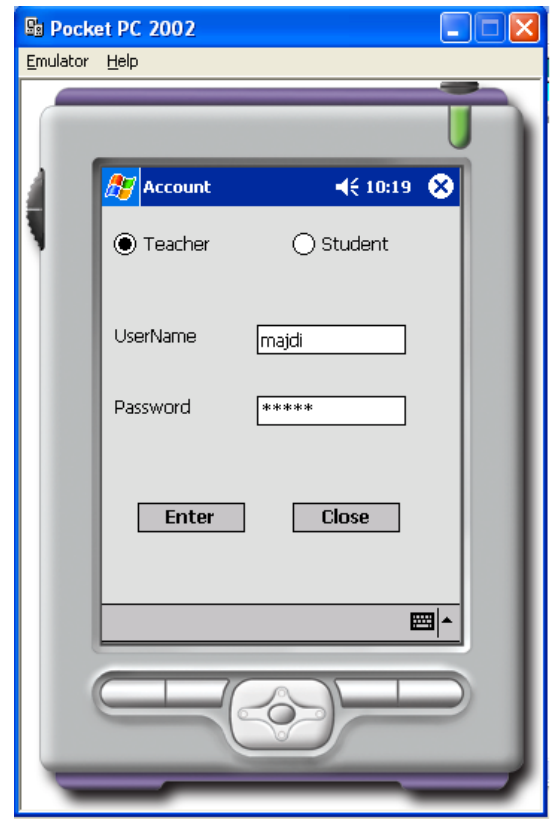

Figure 2 Tutor Login

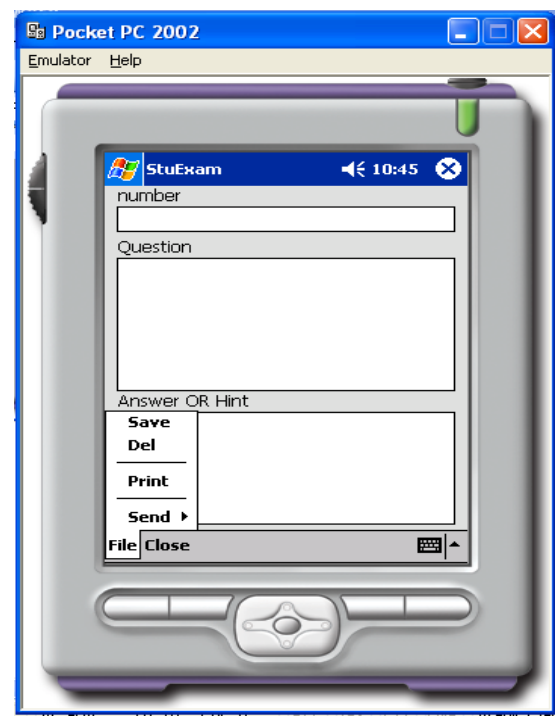

Figure 5 Create questions using Text editor

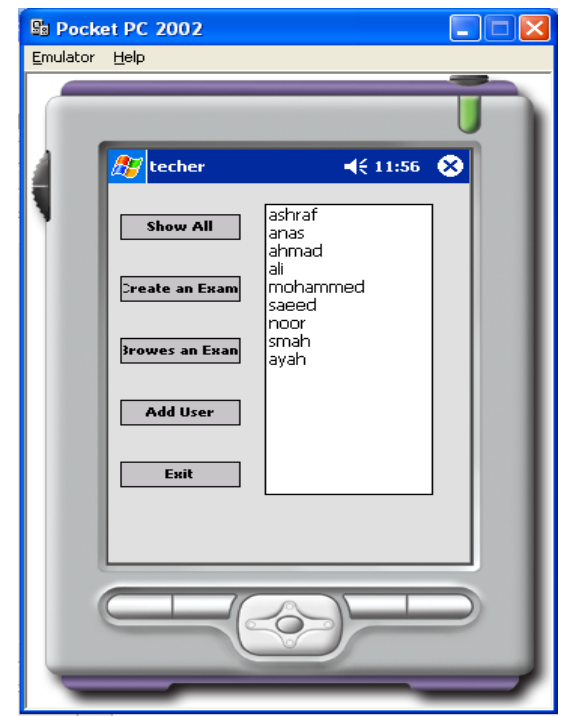

Figure 3 Main Interface

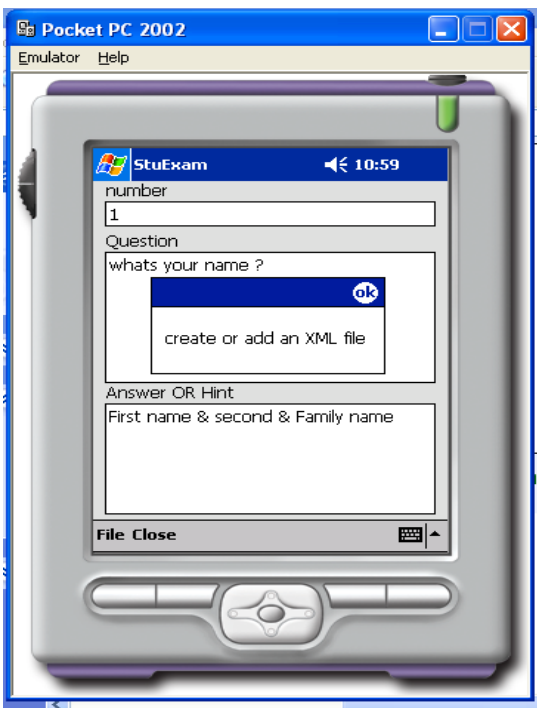

Figure 6 Create an XML file Figure 1
When the tutor enters his username and password into interface shown in figure (2) the interface shown in figure (3) will display. After that, a tutor can browse/show all learners who are connecting now with the Bluetooth of tutor device. So, when the tutor clicks on the first button which labeled (Show All) the names of all learner whom connected will shown at the right of interface in figure (4). Whereas, when he clicks on the second button which labeled (Create an Exam), then the interface shown in the figure (5) will displayed.

Using figure (5), the tutor can put the number or name for questions in the first text box, and the question in the second box, finally a hint or help for this question in the third text box.
After every question the tutor must go to the file menu at the bottom of figure (5) and then select save command to save and creates the XML file. Once the XML file created a tutor can save every question after every question as shown in figure (6).

After that a tutor can send that XML file to all connected learners from the send command in the file menu. The XML file in this example is saved as doc1.txt.

\section{The Learner side}

At the learner side there are also many useful interfaces for the learner, examples of these interfaces are shown in figures 7 to 10 . 


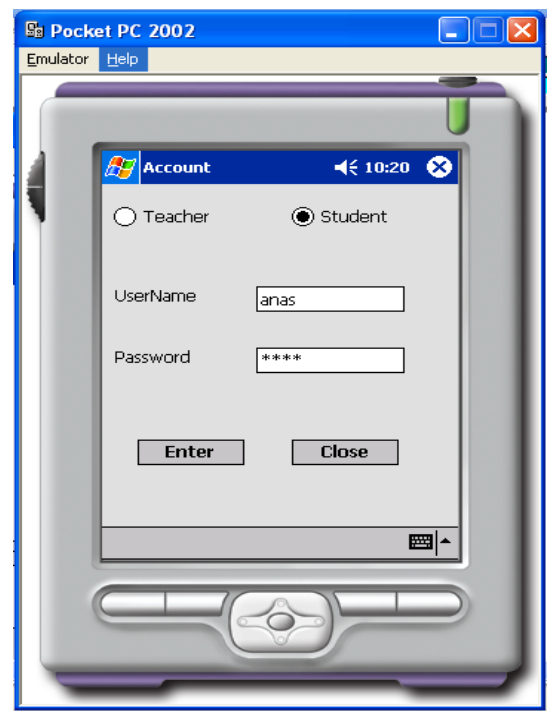

Figure 7. Learner Login

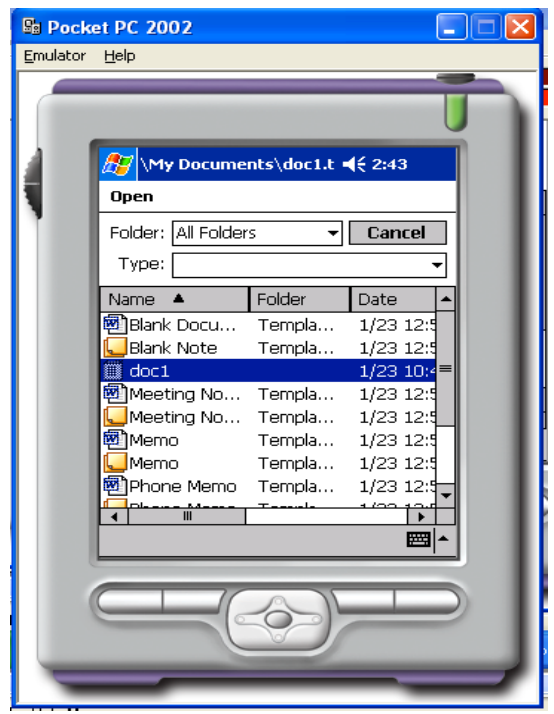

Figure 9. Browse the received files

When the learner enters his username and password into the interface shown in figure (7) and clicks on enter button, then the interface shown in figure (8) will display. This interface consists of five buttons, they are: open, load, save, delete, and send respectively. Using the Open button, a learner can show the exam with its questions after enter the name of the received file which called docl.txt. If the learner does not know the file name he can browse all the files that saved into his device as shown in figure (9), then he can click on the load button to load the received file.

After that the received exam can be browsed questionby-question on the screen of his PDA using the Combo Box labeled with the arrow 1 as shown figure (10), which causes to display the following drop down list.

When a learner select every question and answer it, he must use the file menu and click on save command to save the file with his name and update the XML file. Finally, a learner can send the answered exam or assignment with the same way that the tutor was used. However, there is a

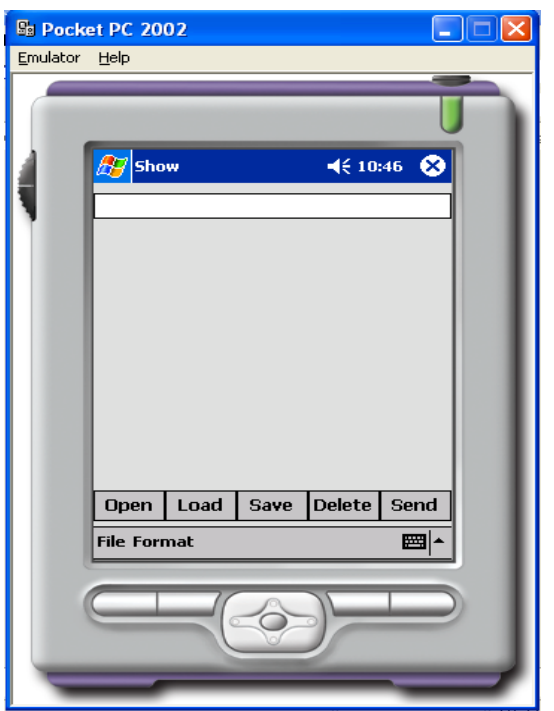

Figure 8. Main Interface

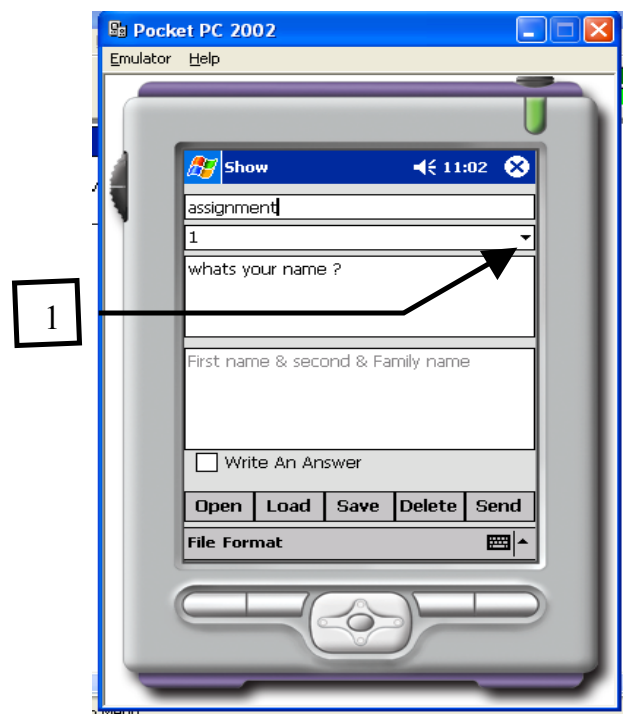

Figure 10. Answer questions

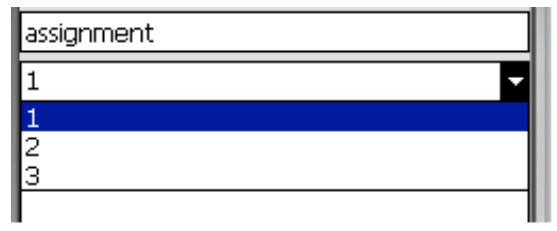

Figure 11. List of questions of an Exam

slight difference between the two ways; which is "the learner can send his file to tutor and just only to the tutor to prevent the cheating". Where the system is developed using the Client/Server architecture: the server side for the tutor, the use at this side can select who will be the receiver, whereas at the client side the learner cannot select who is the receiver. In other words, the receiver at the client side is determined in advance by the administrator of the system (as shown in section 5.1 and figure 2) where the client device search for server device and select it automatically to be as the receiver. 


\section{CONCLUSIONS}

M-learning will not replace traditional learning. It just provides another way of learning using new mobile technology. Of variety of mobile devices available today, smart phones, PDAs and tablet PCs are the most applicable mobile devices for delivering learning. PDAs offer greater functionality than mobile phones and similar advantages to tablet PCs. PDAs, Tablet PCs, and mobile phones can be used in many educational settings and accomplish many different educational tasks. M-learning fulfills the growing demands for life-long learning opportunities that enable learners to "learn while you are on the go". M-learning has already started to play an active and efficient role in E-Learning in Jordan. M-learning has brought E-Learning to the country communities of Jordan. It is a way to E-learning for most learners in Jordan as the growing wireless technology is very important for realizing their access needs. Jordan is moving from inactivated E-Learning to wireless E-Learning. M-learning has an important influence on E-Learning in Jordan. It is growing and improving as being the learning environment of choice.

\section{FUTURE WORK}

Using Wi-Fi can be combined with spreading materials via Bluetooth to widen the range of devices that are able to receive materials which have to be available on each mobile device. Certainly, this will let learners keep their devices on to use them during a lecture; this would require a cultural change in how some educators operate and perceive mobile phones and portable computers.

\section{REFERENCES}

[1] Agrawal, D., "Future Directions in Mobile Computing and Networking Systems". Workshop sponsored by the NSF, University of Cincinnati, 1999.

[2] Alireza N. and Guishi D., "Environmental Factors Influence on Mobile Learning Business", American Journal of Applied Sciences, Vol. 6, 2009, p.p. 1225-1234, 2009.

[3] Andronico, A., Carbonaro, A., Casadei, G., Colazzo, L., Molinari, A., and Ronchetti, M., "Integrating a multi-agent recommendation system into a Mobile Learning Management System", Artificial Intelligence in Mobile System, 2003.

[4] Bonifacio C., Ángel M., Melquíades C., Javier P., “Artificial Intelligence and Bluetooth Techniques in a Multiuser M-learning Domain", International Journal of Computer \& Applications, 2008, Vol. 5, No. 1, pp. 1-13.

[5] Boyinbode O. K. and Akinyede R. O., "Mobile Learning: An Application Of Mobile And Wireless Technologies In Nigerian Learning System", International Journal of Computer Science and Network Security, VOL.8 No.11, 2008, p.p. 386-392.

[6] C. Quinn, M-Learning, "Mobile, Wireless, In-Your-Pocket Learning", http://www. linezine.com/2.1/features/cqmmwiyp.html

[7] Caudill, J., "The Growth of M-learning and the Growth of Mobile Computing - Parallel Developments", International Review of Research in Open and Distance Learning, 2007. (accepted for publication, pending revision).

[8] CeBIT $2004-$ Catch a Glimpse of the Future, http://www.siemensmobile.com
[9] Evgeniya G., Angel S., Tsvetozar G., “A General Classification of Mobile Learning Systems", International Conference on Computer Systems and Technologies, 2005, p.p. IV14.1- IV14.6.

[10] Georgiev, T., Georgieva E., Smrikarov A., "M-Learning - a New Stage of E-Learning", Proceedings of the ComSysTech'2004, 2004, p.p. IV.28-1-IV.28-5.

[11] Jacob S. and Issac B., "The Mobile Devices and its Mobile Learning Usage Analysis", Proceedings of the International MultiConference of Engineers and Computer Scientists, Vol. I, 2008.

[12] Jeanne S., "M-learning using PDA's and our supporting LOMS", International Journal of Computing \& Information Sciences, Vol. 4, No. 2, 2006, p.p. $72-80$.

[13] Kambourakis, G., Kontoni, D-P. N., and Sapounas, I., "Introducing Attribute Certificates to Secure Distributed E-Learning or MLearning Services", Proceedings of the IASTED International Conference, Innsbruck, Australia. 2004, pp 436-440.

[14] Leonard L., "M-learning standards report - Background", discussion and recommendations for usable and accessible m-learning, Commonwealth of Australia, Version 1.0, 2007.

[15] Lonsdale, P., Baber, C., Sharples, M., and Arvanitis, T., "A context awareness architecture for facilitating mobile learning", Proceedings of MLEARN 2003.

[16] Mellow, P., "The media generation: Maximize learning by getting mobile", Proceedings for ascilite 2005: Balance, Fidelity, Mobility: maintaining the momentum, p.p. 469-476.

[17] Pastore1 S., Boccato1 C., Lazzaretto1 E., Nobili1 L., and Benacchio1 L., "The "Learning from Starlight" project experiencing mobile technologies to improve education and outreach of Astrophysics", Recent Research Developments in Learning Technologies, FORMATEX 2005.

[18] Paul A., Adam A., "Mobile and PDA technologies and their future use in education", JISC Technology and Standards Watch: 04-03, 2004.

[19] Ramshirish, M. and Singh, P., "E-learning: Tools and Technology", Proceedings for the DRTC Conference on ICT for Digital Learning Environment, 2006.

[20] Sharples, M., "Big issues in mobile learning", Report of a Workshop by the Kaleidoscope Network of Excellence, Mobile Learning Initiative, University of Nottingham, 2007.

[21] Van T., Tran R., Wong W., K. C., "Mobile Information Exchange and Integration: From Query to Application Layer", the 20th Australasian Database Conference (Conferences in Research and Practice in Information Technol.

\section{AUTHORS}

Mohammed Otair, Associate Professor, The Arab Academy for Banking and Financial Sciences, Department of CIS, Jordan, Amman, Motair@aabfs.org

Mohamad Al-Jedaiah, Assistance Professor, AlAhlyyia Amman University, Jordan, Amman, mohd_noor10@yahoo.com

A. Y. Al-Zoubi, Full Professor, Princess Sumaya University for Technology, Jordan, Amman, zoubi@psut.edu.jo

Anas Al-Refaee, Msc in MIS, The Arab Academy for Banking and Financial Sciences, Department of MIS, Jordan, Amman, anas_alrefae@yahoo.com

Submitted December 13, 2009. Published as resubmitted by the authors February 12, 2010. 